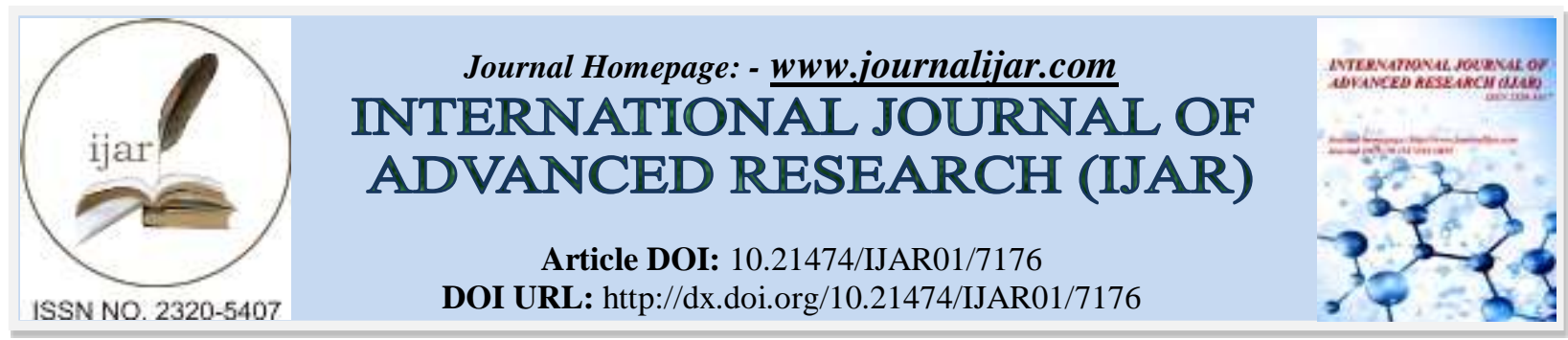

RESEARCH ARTICLE

\title{
PHYTOCHEMICAL SCREENING AND GC-MS ANALYSIS OF POLYHERBAL FORMULATION FOR DIABETES.
}

Revathi. $\mathbf{G}^{\mathbf{1}}$, Elavarasi. $\mathrm{S}^{\mathbf{2}}$ and Saravanan. $\mathrm{K}^{\mathbf{1}}$.

1. PG and Research Dept. of Zoology, Nehru Memorial College (Autonomous), Puthanampatti, Tiruchirappalli, Tamilnadu, South India.

2. PG and Research Dept. of Zoology, Holy Cross College (Autonomous), Tiruchirappalli, Tamilnadu, South India.

\section{Manuscript Info}

(.........................

Manuscript History

Received: 23 March 2018

Final Accepted: 25 April 2018

Published: May 2018

Keywords:-

Polyherbal formulation, Phytochemical screening, GC-MS analyses, Bioactive

compounds, Antidiabetic activity.
Abstract

The present study was carried out to screen the phytochemicals of the polyherbal plants (mixture of Andrographis paniculata, Andrographis alata, Adhatoda zeylanica, Gymnema sylvestre, Syzygium cumini and Justicia glabra) through preliminary phytochemical screening and GCMS analyses. The powder of polyherbal plant mixture was extracted using ethylacetate as solvent. The preliminary phytochemical screening of the extract revealed the presence of bioactive compounds such as flavonoids, alkaloids, carbohydrate, saponin, phenols, triterpenoids, coumarins, emodins and fatty acid and then the extract was subjected to GC- MS analysis. The GC-MS analyses showed the presence of 12 bioactive compounds and these compounds are recommended to treat antidiabetic activity.

Copy Right, IJAR, 2018,. All rights reserved.

\section{Introduction:-}

Plants play a key role in sophisticated ancient traditional medical systems such as traditional Chinese medicine and Ayurveda of India, and have also been central in the Greco-Roman medical tradition, which developed into modern biomedicine. Plants have been used in medicines since time immemorial. Fairly comprehensive information on the curative properties of some herbs has been found recorded in "Charak Samhita" and "Sushruta Samhita" (Kamboj, 2000). The apparent reversal of trend from western to herbal medicine is partly due to the fact that synthetic drugs have always shown adverse reactions and other undesirable side effects. This has led to the belief that natural products are safe because they are more harmonious with biological systems (Revathi et al., 2015). Many more medicinal plants have found potential use as hypoglycemic in the Indian system of medicines, there are 39 plants described. It clearly shows the importance of herbal plants in the treatment of diabetes mellitus (Elavarasi et al 2013). All over the world, plant derived traditional medicine, therefore has an important role in the maintenance of health. Some major categories of plant derived products include personal care products and phyto-cosmetics, herbal medicines, natural health products and phyto-pharmaceuticals (Rasika et al., 2011). It is believed that crude extract from medicinal plants are more biologically active than isolated compounds due to their synergistic effects (Jana, 2010). Phytochemical screening of plants has revealed the presence of numerous chemicals including alkaloids, flavonoids, tannins, steroids, glycosides and saponins. The Ethnobotanical study was conducted in the Kolli hills, Tamil Nadu through an oral interview to investigate the medicinal plants used in the treatment of Diabetes. However, prominent side effects of such drugs are the main reason for an increasing number of people seeking alternative therapies that may have less severe or no side effects. (Elavarasi and Saravanan, 2012; Elavarasi et al., 
2013). The polyherbal plants (mixture of Andrographis paniculata, Andrographis alata, Adhatoda zeylanica, Gymnema sylvestre, Syzygium cumini and Justicia glabra) possessed antimicrobial activity, anti-inflammatory activity, antifungal activity and antidiabetic activity (Revathi et al., 2015). The present study was carried out to determine the phytochemical constituents of polyherbal extract by using GCMS. This study will provide another useful resource for future.

\section{Materials and Methods:-}

Preparation of extracts

The Polyherbal drug was prepared by mixing equal quantity of whole plant of A. paniculata, A. alata, G. sylvestre and J. glabra, leaves of A. zeylanica, and bark of $S$. cumini powder. Then it was extracted by cold extraction method using ethylacetate. They were concentrated to a dry mass by vacuum evaporator and stored separately in desiccator until use.

\section{Preliminary phytochemical screening}

Different extracts of polyherbal mixer were subjected to screen the preliminary phytochemicals such as alkaloids, flavonoids, glycosides, phenolic compounds, saponins, terpenoids, steroids, tannins, fatty acids, protein and carbohydrate according to the standard methods (Kokate, 1994; Harborne, 1973; Rajpal, 2002; Raman, 2006).

Test for flavonoids: One $\mathrm{ml}$ of extract was taken in a test tube and a few drops of dilute sodium hydroxide were added. An intensive yellow colour is produced and become colourless on addition of few drops of dilute $\mathrm{HCl}$ which indicates the presence of flavonoids.

Test for alkaloids: Extract $(0.5 \mathrm{~g})$ was diluted to $10 \mathrm{ml}$ with acid alcohol then boiled and filtered. Two $\mathrm{ml}$ of dilute ammonia was added to $5 \mathrm{ml}$ of the filtrate. Then $5 \mathrm{ml}$ of chloroform was added to this content and shaken gently. The chloroform layer was extracted with $10 \mathrm{ml}$ of acetic acid which was divided into two portions. Mayer's reagent was added to one portion and Draggendorff's reagent to the other. The formation of a cream with Mayer's reagent or reddish brown precipitate with Draggendorff's reagent indicates the presence of alkaloids.

Test for tannins: About $0.5 \mathrm{~g}$ of the extract was boiled in $10 \mathrm{ml}$ of water in a test tube and then filtered. Few drops of $0.1 \%$ ferric chloride was added and observed for brownish green or a blue-black colouration which indicates the presence of tannins.

Test for saponins: Extract $(0.5 \mathrm{~g})$ was taken in a test tube and $5 \mathrm{ml}$ of distilled water added. This mixture was shaken vigorously and observed for a stable persistent froth. That froth was mixed with 3 drops of olive oil and shaken vigorously. The formation of an emulsion indicates the presence of saponins.

Test for glycosides: The extract was hydrolysed by hydrochloric acid for few hours on a water bath. Then $1 \mathrm{ml}$ of pyrimidine and a few drops of sodium nitroprusside solutions were added to this hydrolysate. Then it was made alkaline by adding sodium hydroxide solution. Appearance of pink to red colour showed the presence of glycosides.

Detection of phenols: Presence of phenols was detected by ferric chloride test. Extract was treated with 3 to 4 drops of ferric chloride solution. Formation of bluish black colour indicates the presence of phenols.

Test for steroids: One $\mathrm{ml}$ of the extract was dissolved in $10 \mathrm{ml}$ of chloroform and equal volume of concentrated sulphuric acid was added by sides of the test tube. Formation of yellow with green fluorescence colour indicates the presence of steroids.

Test for triterpenoids: Ten milligram of the extract was dissolved in $1 \mathrm{ml}$ of chloroform; $1 \mathrm{ml}$ of acetic anhydride was added following the addition of $2 \mathrm{ml}$ of Conc. $\mathrm{H}_{2} \mathrm{SO} 4$. Formation of reddish violet colour indicates the presence of triterpenoids.

Test for emodins: Two $\mathrm{ml}$ of $10 \% \mathrm{NH}_{4} \mathrm{OH}$ and $3 \mathrm{ml}$ of benzene was added to the extract. Appearance of red colour indicates the emodins.

Test for Coumarins: $3 \mathrm{ml}$ of $10 \% \mathrm{NaOH}$ was added to $2 \mathrm{ml}$ of extract. Formation of yellow color indicates the presence of coumarins.

Test for fatty acids: $0.5 \mathrm{ml}$ of extract was mixed with $5 \mathrm{ml}$ of ether. These extract was allowed it for evaporation, on filter paper and dried the filter paper. The appearance of transparence on filter paper indicates the presence of fatty acids (Ayoola et al., 2008).

Test for proteins: The extract was treated with few drops of concentrate nitric acid. Formation of yellow colour indicates the presence of proteins. 
Test for carbohydrates: Extract was dissolved in $5 \mathrm{ml}$ of distilled water and filtered. The filtrate was used to test for the presence of carbohydrates. Filtrate was treated with 2 drops of alcoholic $\alpha$-naphthol solution in a test tube. Formation of the violet ring at the junction indicates the presence of carbohydrates.

GC-MS analysis:-

Presence of individual compounds in the study plant extracts were analyzed using GC-MS/MS of Thermo Fisher make, ITQ900 model. One micro liter of the sample was run in a DB-1 fused silica capillary column with helium $(1 \mathrm{ml} / \mathrm{min})$ as carrier gas, $250^{\circ} \mathrm{C}$ injector temperature, $280^{\circ} \mathrm{C}$ ion-source temperature and isothermal temperature $110^{\circ} \mathrm{C}(2 \mathrm{~min})$, with an increase of $10^{\circ} \mathrm{C} / \mathrm{min}$ to $200^{\circ} \mathrm{C}$ then $5^{\circ} \mathrm{C} / \mathrm{min}$ to $280^{\circ} \mathrm{C}$ and 9 min to $280^{\circ} \mathrm{C}$. The mass spectrum interpretation was performed using the library of National Institute Standard and Technology (NIST) and the compounds were identified.

\section{Results and Discussion:- \\ Phytochemical screening}

The results showed the presence of flavonoids, alkaloids, carbohydrate, saponin, phenols, triterpenoids, coumarins, emodins and fatty acids in the ethylacetate extract of polyherbal plant drug (Table 1). Polyherbal drug can able to reduce blood glucose level due to the presence of above chemical fractions. Even though, this is only a preliminary study of the occurrence of certain chemicals of polyherbal drug isolation and characterization of chemical constituents would provide a good concrete base of all the phytochemicals functions. The phytochemical screening result showed the presence of 26 bioactive compounds from all the solvent extracts from the $N$. cadamba leaves and some of the identified compounds have been reported to possess various biological activities such as anti-microbial, anti-cancer, antimutagenic, antipeptic, antiseptic, antispasmodic, anti-adrenogenic and hypocholesterolemic activities as summarized (Zayed et al., 2014) Palmitic acid is an intermediate in the biosynthesis of sexual pheromones of some insects (Trabalon et al., 2005). It is used in the preparation of the ingredients of some drugs to decrease the hydrophobicity of virginiamycin, a drug used against Mycobacterium avium (Rastogi et al., 1998; Mingarro et al., 2008) and it is well known as insecticide and anti-microbial agents (Praveen et al., 2010) Myristic acid is one of saturated fatty acids in animal and vegetable fats that are commonly used in soaps, cosmetics, flavourings and perfumes. It has hypercholesterolemic activity as it increases low density lipoprotein cholesterol production (Huges et al., 1996).

Table 1:- Preliminary phytochemical screening of ethylacetate extracts of Polyherbal drug

\begin{tabular}{|c|c|c|}
\hline S. No. & Name & Ethyl acetate extract \\
\hline 1 & Flavonoids & $(+)$ \\
\hline 2 & Alkaloids & $(-)$ \\
\hline 3 & Tannin & $(-)$ \\
\hline 4 & Protein & $(+)$ \\
\hline 5 & Carbohydrate & $(+)$ \\
\hline 6 & Saponin & $(-)$ \\
\hline 8 & Glycosides & $(+)$ \\
\hline 10 & Phenols & $(+)$ \\
\hline 12 & Sterols & $(+)$ \\
\hline 14 & Triterpenoids & $(+)$ \\
\hline
\end{tabular}

$(+)=$ Present $\quad(-)=$ Absent

\section{GC-MS studies}

Totally 12 compounds were identified in the spectrum profile of GC-MS of ethylacetate extract of polyherbal drug. The present study showed the spectrum profile of GC-MS confirmed the presence of towel major components with retention time of $22.33,12.52,23.13,26.67,17.82,19.52,15.75,19,17.18$ and 20.65. Identified compounds were Perivin, Phenol, 2,,4-bis (1,1-dimethylethyl)- 4,4,4' - Trimethoxytrityl alcohol, 1,6- heptadiene- 3,5- dione, 1,7bis(4- hydroxyl-3 methoxyphenyl)-, Rhein, Morin, Flavone, Nonivamide,Coumarin, 8- acetyl- 7- hydroxyl -4methyl-, Coumarin, 4- hydroxyl-3-(Phydroxyphenyl)- 5,7- dimethoxy, Coumarin,8-acetyl-7-hydroxy-4-methyl, 4H1 Benzopyran- 4- one 5,7- dihydroxy- 3- phenyl-.The fragmentations of the components are illustrated in GC-MS 
chromatogram (Table 2 and Figure 1). GC-MS analysis 12 prominent compounds were identified and out of which 2 compounds viz., Hexadecanoic acid and octadecenoic acid have already proved as antidiabetic activity by possessing insulin secretion, insulin stimulation, $\alpha$-glucosidase inhibitors (Balogun et al., 2013; Wuttke et al., 2013). The GCMS analysis of various compounds from $N$. aragoana rhizome extracts was performed using Perkin Elmer Elite 5 capillary column and typical total ion chromatograms (TIC) of each sample were given in fig. 3, 4, 5 and 6 respectively. The comparison of the mass spectrums with the data base gave more than $90 \%$ match as well as confirmatory compound structure match. The GCMS analysis of the concentrated ethanol extract, ether extract, methanol extract resulted many compounds which have diverse use. Compounds having anti-inflammatory, antibacterial, antifungal, skin conditioning properties have been identified. The plant is extensively used as a diuretic traditionally in India (Thomas et al., 2013).

Table 2:- Identified compounds from ethyacetate extract of polyherbal formulation by GC-MS analysis

\begin{tabular}{|c|c|c|c|c|}
\hline S. No & Compound name & Molecular formula & M.W & R.T \\
\hline 1 & Perivin & $\mathrm{C}_{20} \mathrm{H}_{22} \mathrm{~N}_{2} \mathrm{O}_{3}$ & 338 & 22.33 \\
\hline 2 & Phenol, 2,4- bis (1,1- dimethylethyl)- & $\mathrm{C}_{14} \mathrm{H}_{22} \mathrm{O}$ & 206 & 12.52 \\
\hline 3 & 4,4,4" Trimethoxytrityl alcohol & $\mathrm{C}_{21} \mathrm{H}_{20} \mathrm{O}_{3}$ & 320 & 23.13 \\
\hline 4 & Pseudobaptigenin & $\mathrm{C}_{16} \mathrm{H}_{10} \mathrm{O}_{5}$ & 282 & 17.67 \\
\hline 5 & $\begin{array}{c}\mathrm{C}_{21} \mathrm{H}_{20} \mathrm{O}_{6} \\
\text { 1,6-Heptadiene- 3,5- dione, 1,7- bis(4- hydroxyl- } \\
\text { 3- methoxyphenyl }\end{array}$ & 368 & 27.67 \\
\hline 6 & Rhein & $\mathrm{C}_{21} \mathrm{H}_{20} \mathrm{O}_{6}$ & 368 & 17.82 \\
\hline 7 & Morin & $\mathrm{C}_{15} \mathrm{H}_{10} \mathrm{O}_{7}$ & 302 & 19.52 \\
\hline 8 & Flavone & $\mathrm{C}_{15} \mathrm{H}_{10} \mathrm{O}_{2}$ & 222 & 15.75 \\
\hline 9 & Nonivamide & $\mathrm{C}_{17} \mathrm{H}_{27} \mathrm{NO}_{3}$ & 293 & 19 \\
\hline 10 & $\mathrm{C}_{12} \mathrm{H}_{10} \mathrm{O}_{4}$ & 218 & 17.18 \\
\hline 11 & Coumarin,8-acetyl-7-hydroxy-4-methyl & 254 & 15.85 \\
\hline 12 & $\begin{array}{c}\mathrm{C}_{15} \mathrm{H}_{10} \mathrm{O}_{4} \\
\text { phenyl- }\end{array}$ & & 124 & 20.65 \\
\hline
\end{tabular}

Figure 1:- GC-MS Chromatogram of Ethylacetate extract of polyherbal formulation

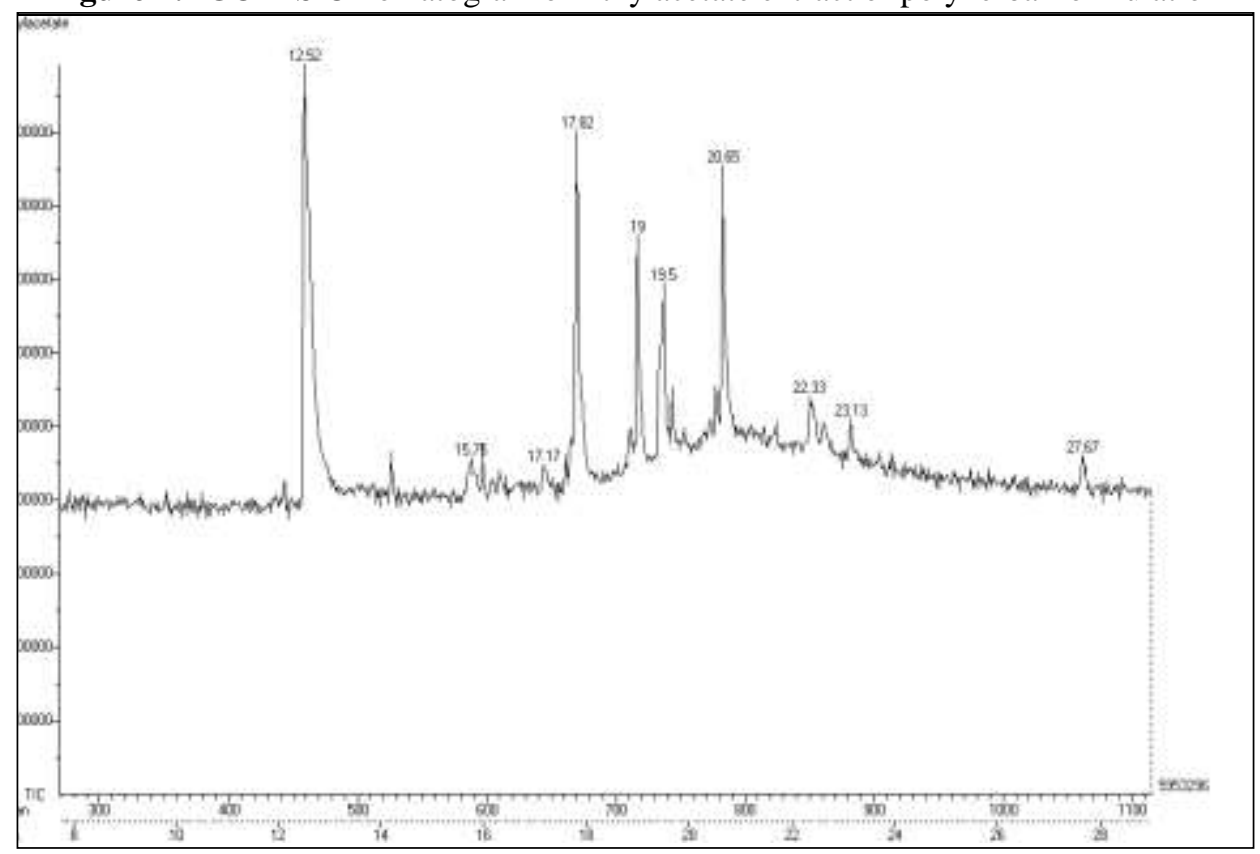




\section{Conclusion:-}

The phytochemistry screening of the extract of polyherbal drug showed the presence of flavonoids, alkaloids, carbohydrate, saponin, phenols, triterpenoids, coumarins, emodins and fatty acids. Totally 12 compounds were identified in the spectrum profile of GCMS of ethylacetate extract of polyherbal drug and some of the identified bioactive compounds possesses antidiabetc activity. Thus the polyherbal formulation is used for further evaluation of antidiabetic activity.

\section{Acknowledgement:-}

The authors thank the Management, Principal and Head of the Department for providing the necessary facilities. We thank UGC -New Delhi, for financial assistance.

\section{References:-}

1. Ayoola, G.A., Coker, H.A.B., Adesegun, S.A., Adepoju-Bello, A.A., Obaweva, K., Ezennia, E.C and Atangbayila, T.O (2008). Phytochemical screening and antioxidant activities of some selected medicinal plants used for malaria therapy in Southwestern Nigeria. Trop. J. Pharm. Res., 7: 1019-1024.

2. Balogun, O.S., Oladosu, I.A., Akinnusi, A and Zhiqiang, L. (2013). Fatty acids composition, $\alpha$-glucosidase inhibitory potential and cytotoxicity activity of Oncoba diacylglycerol signaling microdomains in $\beta$ cells promote insulin secretion. FASEB. J., 27(4):1610-20.

3. Elavarasi S and Saravanan K. (2012). Ethnobotanical study of plants used to treat diabetes by tribal people of Kolli Hills, Namakkal district, Tamilnadu, Southern India. International Journal of Pharm Tech Research,4: 404-411.

4. Elavarasi, S., Saravanan, K and Renuka, C. (2013). A systematic review on medicinal plants used to treat diabetes mellitus. International Journal of Pharmaceutical, Chemical and Biological Sciences, 3(3): 983 - 992.

5. Harborne, J. B. (1973). Phytochemical methods. Chapman and Hall Ltd., London.

6. Huges, TA., Heimberg, M, and Wang X. (1996). Comparative lipoprotein metabolism of myrisate palmitate and stearate in normalipidemic man metabolism. Int J Res Pharm Sci., 5(9):1108-18.

7. Jana S, and Shekhawat GS. (2010). Res J Med Plant, 4:206-212.

8. Kokate, C.K (1994). Pharmacohnosy. 16th edition, Nirali Prakasham Publication, Mumbai, India.

9. Mingarro, I., Lukovic, D., Vilar, M, and Perez-Gil J. (2008). Synthetic pulmonary surfactant preparations: new developments and future trends. Current Medicinal Chemistry, 15(4):393-403.

10. Praveen, KP. Kumaravel, S, and Lalitha C. (2010). Screening of antioxidant activity, total phenolics and GCMS study of Vitex negundo. African J Biochemistry Res, 4(7):191-5.

11. Rajpal, V (2002). Standardization of Botanicals Testing and Extraction Methods of Medicinal Herbs. Eastern Publishers, New Delhi.

12. Raman, N. (2006). "Phytochemical techniques". New Delhi: New India Publishing Agency.12.

13. Rasika C, Torane et al. (2011). Int.J.Chem tech Res. 3(3).

14. Rastogi, N., Moreau, B., Capmau, ML. Goh, KS, and David, HL. (1988). Antibacterial action of amphiphatic derivatives of isoniazid against the Mycobacterium avium complex. Zentralblatt für Bakteriologie, Mikrobiologie und Hygiene, 268:456-62.

15. Revathi G, Elavarasi.S and Saravanan.K. (2015). Evaluation of toxic effect of traditionally used antidiabetic polyherbal formation on albino rats. Int J Pharm Bio Sci., 6(4): 181 - 187.

16. Thomas, E., Aneesh, T., Thomas, D, and Anandan, R. (2013). GCMS analysis of Phytochemical compounds present in the rhizomes of Nervilia aragona gaud. Asian J Pharm Clin Res, 6(3):68-74.

17. Trabalon, M., Niogret, J, and Legrand-Frossi, C. (2005). Effect of 20-hydroxyecdysone on cannibalism, sexual behavior, and contact sex pheromone in the solitary female spider, Tegenaria atrica. General Comparative Endocrinology 144:60-6.

18. Wuttke, A, Idevall-Hagren, $\mathrm{O}$ and (2013). Tengholm A. P2Y ${ }_{1}$ receptor-dependent spinosa Forssk. Elixir Appl. Chem., 59: 15637-15641.

19. Zayed, MZ. Ahmad, F.B., Ho, W S, and Pang, SL. (2014). GCMS analysis of phytochemical constituents in leaf extracts of Nelamarckia cadamba (Rubiaceae) from Malaysia. Int J Pharm Pharm Sci, 6 (9): 123-127. 